Faculty of Science

Faculty Publications

Operators of Fractional Calculus and Their Applications

Hari Mohan Srivastava

2018

(C) 2018 by the authors. Licensee MDPI, Basel, Switzerland. This article is an open access article distributed under the terms and conditions of the Creative Commons Attribution (CC BY) license ( http://creativecommons.org/licenses/by/4.0/ ).

This article was originally published at:

https://doi.org/10.3390/math6090157

Citation for this paper:

Srivastava, H.M. (2018). Operators of Fractional Calculus and Their Applications.

Mathematics, 6(9), 157. https://doi.org/10.3390/math6090157 


\title{
Editorial
}

\section{Operators of Fractional Calculus and Their Applications}

\author{
Hari Mohan Srivastava ${ }^{1,2}$ \\ 1 Department of Mathematics and Statistics, University of Victoria, Victoria, BC V8W 3R4, Canada; \\ harimsri@math.uvic.ca \\ 2 Department of Medical Research, China Medical University Hospital, China Medical University, \\ Taichung 40402, Taiwan
}

Received: 4 September 2018; Accepted: 4 September 2018; Published: 5 September 2018

Website: http://www.math.uvic.ca/faculty/harimsri/

This volume contains the successfully invited and accepted submissions (see [1-9]) to a Special Issue of MDPI's journal, Mathematics in the subject area of "Operators of Fractional Calculus and Their Applications".

The subject of fractional calculus (that is, calculus of integrals and derivatives of any arbitrary real or complex order) has gained considerable popularity and importance over the past four decades, due, mainly, to its demonstrated applications in numerous diverse and widespread fields of science and engineering. It does indeed provide several potentially useful tools for solving differential, integral, and integro-differential equations, and various other problems involving special functions of Mathematical Physics and Applied Mathematics as well as their extensions and generalizations for one and more variables.

The suggested topics of interest for the call of papers for this Special Issue included, but were not limited to, the following keywords:

- Operators of fractional calculus

- Chaos and fractional dynamics

- Fractional differential

- Fractional differintegral equations

- Fractional integro-differential equations

- Fractional integrals

- Fractional derivatives

- Special Functions of Mathematical Physics and Applied Mathematics

- Identities and inequalities involving fractional integrals

Here, in this Editorial, we briefly describe the status of the Special Issue, as follows:

1. Publications: $(8+1)$;

2. Rejections: (16);

3. Article Average Processing Time: 43 days;

4. Article Type: Research Article (8); Review (0); Correction (1)

Authors' geographical distribution:

- Canada (2)

- Korea (2)

- Japan (1)

- India (1)

- $\quad$ Thailand (1)

- $\quad$ Slovakia (1)

- $\quad$ People's Republic of China (1) 
- $\quad$ Taiwan (Republic of China) (1)

- $\operatorname{Jordan}(1)$

- $\quad$ USA (1)

The very first work to be devoted exclusively to the subject of fractional calculus, was published in 1974. Ever since then, numerous monographs and books as well as scientific research journals have appeared in the existing literature on the theory and applications of fractional calculus.

Several well-established scientific research journals, published by such publishers as (for example) Elsevier Science Publishers, Hindawi Publishing Corporation, Springer, De Gruyter, MDPI, and others, have published and continue to publish a number of Special Issues in many of their journals on recent advances in different aspects of the subject of fractional calculus and its applications. Many widely-attended international conferences, too, continue to be successfully organized and held worldwide ever since the very first one on this subject in USA in the year 1974.

Conflicts of Interest: The author declares no conflict of interest.

\section{References}

1. Singh, Y.M.; Khan, M.S.; Kang, S.-M. F-Convex contraction via admissible mapping and related fixed point theorems with an application. Mathematics 2018, 6, 105. [CrossRef]

2. Li, C.-K.; Li, C.P.; Clarkson, K. Several results of fractional differential and integral equations in distribution. Mathematics 2018, 6, 97. [CrossRef]

3. Li, C.-K.; Clarkson, K. Babenko's approach to Abel's integral equations. Mathematics 2018, 6, 32. [CrossRef]

4. Morita, T.; Sato, K.-I. Solution of inhomogeneous differential equations with polynomial coefficients in terms of the green's function. Mathematics 2017, 5, 62. [CrossRef]

5. Fečkan, M.; Wang, J.-R. Mixed order fractional differential equations. Mathematics 2017, 5, 61. [CrossRef]

6. Yensiri, S.; Skulkhu, R.J. An investigation of radial basis function-finite difference (RBF-FD) method for numerical solution of elliptic partial differential equations. Mathematics 2017, 5, 54. [CrossRef]

7. Lee, Y.-H. Stability of a monomial functional equation on a restricted domain. Mathematics 2017, 5, 53. [CrossRef]

8. Thabet, H.; Kendre, S.; Chalishajar, D.K. New analytical technique for solving a system of nonlinear fractional partial differential equations. Mathematics 2017, 5, 47. [CrossRef]

9. Thabet, H.; Kendre, S.; Chalishajar, D.K. Correction: Thabet, H.; Kendre, S.; Chalishajar, D.K. New analytical technique for solving a system of nonlinear fractional partial differential equations Mathematics 2017, 5, 47. Mathematics 2018, 6, 26. [CrossRef]

(C) 2018 by the authors. Licensee MDPI, Basel, Switzerland. This article is an open access article distributed under the terms and conditions of the Creative Commons Attribution (CC BY) license (http:// creativecommons.org/licenses/by/4.0/). 